\title{
DILEMAS DE UMA CULTURA NORMATIVA: PLURALISMO JURÍDICO E FAVELA*
}

\author{
Renan Aguiar $^{* *}$
}

Resumo: O presente trabalho problematiza a relação entre a população de uma favela da região serrana do Estado do Rio de Janeiros e as instituições de Estado. Analisa-se a cultura normativa e seus vínculos com os universos da fé, da política e da justiça, identificando-se alguns elementos e valores estranhos ao universo das normas jurídico-estatais

Palavras Chave: Pluralismo jurídico; cultura normativa da favela; cultura normativa e religiosidade; favela e religiosidade; administração da justiça.

\section{DILEMMAS OF A NORMATIVE CULTURE: LEGAL PLURALISM AND FAVELA.}

Abstract: The present work appoints the problematic relationship between the people from a favela in the mountain region of the State of Rio de Janeiro and the State institutions. It is analyzed the normative culture and its connections with the universes of faith, politics and justice, being identified some strange elements and values to the universe of the state legal norms.

Keywords: Legal pluralism; favela`s normative culture; normative culture and religiosity; favela and religiosity; justice administration.

\section{Introdução}

Este trabalho é o resultado da pesquisa "De Pasárgada à Quinta Lebrão" e tem como objetivo expor dados e reflexões sobre os espaços de mediação não estatais de conflitos e litígios que, de uma certa forma, seriam resolvidos na justiça formal. $\mathrm{O}$ tema em si não é novo e já foi tratado em trabalhos clássicos como O Discurso e o Poder (SANTOS, 1988) que data dos fins dos anos 60 e começo dos 70, fase em que o Brasil vivia sob um regime militar. Baseado em esquemas canônicos do período, tal como a teoria da marginalidade urbana e outros tantos de influência marxista, $O$ Discurso e o Poder redimensiona essa linha o autor elege como objeto de análise sociológica um processo pelo qual uma determinada

\footnotetext{
* Este trabalho utilizou dados da pesquisa desenvolvida por Renan Aguiar e Marcelo Lacombe, cujo relatório final está disponível em: AGUIAR, Renan; LACOMBE, Marcelo Masset; RAPOSO, Marcelo. De Pasárgada à Quinta Lebrão: direito dos excluídos. Teresópolis: Publit.

** Renan Aguiar é doutor em Direito pela Universidade Federal Fluminense, mestre em Direito pela Pontifícia Universidade Católica do Rio de Jambeiro (PUC-Rio), advogado e bacharel em Direito pela Universidade Federal do Estado do Rio de Janeiro. e-mail: renan.aguiar@aguiar.rio.br
} 
comunidade de baixa renda cria, a partir do confronto com as suas condições reais e concretas de vida, um direito próprio, um direito alternativo produzido em condições de marginalidade social. Portanto, uma condição muito específica e sui generis da luta de classes na América Latina, uma situação que Marx certamente não viu. Assim, o direito alternativo seria uma resposta das classes populares à condição de marginalidade urbana, de pobreza e de exploração em que viviam. Desta forma, não se trata mais de pensar o direito como reflexo do modo de pensar de uma classe dominante, mas sim de pensar um direito criado pela classe dominada como uma resposta à dominação que a subjuga. $\mathrm{O}$ direito de Pasárgada (nome fictício da favela do Jacarezinho) seria assim não um direito burguês, mas um direito das classes trabalhadoras, em situação de marginalidade social, que visam fazer frente a uma ausência do direito burguês como um mecanismo tanto de dominação como de integração social. Nesse sentido, Santos (1988) encontra uma insuficiência na reflexão marxista sobre o tema do direito pensando-o através de um contexto peculiar em que uma grande parcela da classe trabalhadora está marginalizada das conquistas modernas do direito burguês. Isto é, no contexto de um capitalismo periférico e dependente, a sociedade do contrato existe, mas não é para todos e não incorpora a sociedade como um todo. Contudo, se o direito burguês é um reflexo do modo de pensar da burguesia, também o direito de Pásargada o será em relação ao grupo social que lhe dá origem. Isso permitiu a Santos (1988) tratar da questão nos termos de uma luta de classes e ver na emergência de um direito alternativo um dado de politização das classes dominadas.

A retomada do tema que anima esta pesquisa no início deste século XXI decorre da preocupação com processos sociais que criam uma situação social análoga, mas substancialmente diferente daquilo que era objeto de indagação da teoria da marginalidade, ou seja, aquilo que se convencionou chamar de exclusão social. Os processos excludentes condicionados por mudanças profundas, na esfera da produção, decorrentes da globalização, cria, em interação com processos históricos locais em relação à América Latina, e no caso o Brasil, uma situação social nova. Neste contexto histórico marcado também pela longa redemocratização do país, o tema abordado por Santos (1988) se vê inserido num contexto diferenciado. Fato é que este processo de redemocratização impôs uma agenda política em que a questão social se torna aspecto capital das demandas sociais. Cabe então, no projeto de consolidação de uma democracia liberal burguesa em terras brasileiras promover uma integração social através da ampliação da esfera dos direitos sociais e políticos, ou seja, da 
expansão da sociedade do contrato como uma forma de combater o que se chama hoje de exclusão social. Assim, temas da favela, dos bairros pobres, da pobreza urbana voltam ao discurso político e ao discurso acadêmico, algumas vezes, referenciados na produção intelectual das décadas de 60 e 70, mas em grande parte esquecendo a produção do passado (Valladares, 2005)

Se a favela é e foi uma criação intelectual e simbólica na medida em que suscitou uma gama ampla de representações sociais ao longo dos cem anos de sua existência (Valladares, 2005), também é inegável que nos últimos anos tais representações acentuaram aspectos de problema constrangedor na construção de uma ordem liberal e democrática, assim, a favela é vista como um espaço social do tráfico de drogas, da violência e da criminalidade, além de ser o lugar da pobreza e símbolo mor da segregação urbana. Mas, como aponta Valladares (2005), a favela não é apenas isso, sendo um conjunto social muito amplo, vasto e diferenciado para se enquadrar nos rótulos fáceis do discurso militante ou da mídia. É inegável também que tais representações contribuem de forma significativa para a estigmatização da favela, provocando medo e apreensão nos moradores das áreas urbanas vizinhas e desvalorizando os imóveis que se situam próximos das favelas. O fato é que passar por uma favela durante a noite dá medo e cruzar na rua com uma pessoa que se identifica pela pura aparência como favelado já suscita a dúvida de se tratar de um bandido, traficante. Assim, as representações sociais que se fazem em relação a favela constituem efeitos reais que tangem as questões capitais de uma sociedade que adere a um projeto liberal democrático de igualdade e cidadania. Por isso é natural a reivindicação das comunidades faveladas ao acesso à justiça e aos benefícios que a consolidação de tal projeto traria.

Um ponto importante a ser levantado é o fato de que tais representações das favelas, de acordo com o estudo de Lícia do Prado Valladares (2005), se deram a partir da experiência dos grandes centros urbanos do Brasil, as favelas de São Paulo e Rio de Janeiro. Isso porque sempre se associou a favela com os processos intensos de urbanização que o Brasil viveu ao longo do séc. XX, mas o caso empírico que tomamos para a nossa análise foi o de uma favela de uma cidade do interior fluminense situada na região serrana. Teresópolis é uma cidade média com pouco menos de 150 mil habitantes e responsável por apenas 16,1\% do PIB da região serrana do Rio de Janeiro. É uma cidade fortemente ligada à capital do estado como cidade de veraneio e tem servido de residência para uma classe média carioca que ainda trabalha na capital do estado à uma hora e meia de viagem. A grande atividade econômica da 
cidade está ligada ao mercado imobiliário e à construção civil, sendo que parte significativa do seu PIB advém da prestação de serviços e do comércio varejista. Contudo, Teresópolis é uma cidade permeada de favelas, entre elas a comunidade de Quinta Lebrão onde grande parte dos habitantes são trabalhadores da construção civil, pedreiros, encanadores, pintores.

O contexto empírico que tomamos para realizar a pesquisa é substancialmente diferente do contexto da pesquisa de Santos (1988). Assim, o objetivo desta pesquisa não é o de simplesmente atualizar uma perspectiva teórica de análise pela retomada do objeto, mas sim dar conta de refletir sobre como as camadas populares dão respostas diferentes em situações e contextos históricos diferentes em relação a uma mesma questão: o direito como mecanismo de integração social. O trabalho empírico realizado junto à comunidade de Quinta Lebrão buscou levantar questões e refletir sobre as condições de vida atuais da população em questão partindo do direito como mecanismo de integração social. Isto posto, o que encontramos em Quinta Lebrão não foi nem pluralismo jurídico e nem qualquer forma de direito alternativo, mas sim um conjunto complexo de sistemas simbólicos que articulam as relações da comunidade com o mundo social mais amplo. Tais sistemas simbólicos configuram um conjunto de ambigüidades e dualidades normativas em que estão imersos e embebidos os espaços de mediação de conflitos e litígios. Estes, por sua vez, se encontram institucionalizados no interior da comunidade e executam também o trabalho de mediação entre esta e o mundo social mais amplo. Neste sentido, a realidade observada é fundamentalmente diferente daquela analisada por Santos (1988) e por isso traz um conjunto de indagações e reflexões diferenciadas. Tais indagações trazem as marcas do contexto histórico em que o fenômeno se dá, aí é que temos todo um conjunto de diferenças que separam as associações de moradores dos tempos de Boaventura das deste começo de século. Disso se percebe também toda uma re-significação da esfera da atuação política que começa a se embeber em elementos semânticos religiosos profundamente marcados pela ética cristã. Tal ética e tal conjunto semântico não apenas configuram uma normatividade específica, mas é também um esforço de reconstrução simbólica de um mundo social mais vasto que marca a religiosidade de uma população parte das classes dominadas. Assim, é através de uma normatividade específica que marca as práticas sociais de um determinado grupo que percebemos estratégias simbólicas de superação da situação de exclusão social e da marca de estigma que esse tipo de situação acarreta. No entanto, é nesse quadro que se dão os 
complexos conjuntos de dualidades e ambigüidades normativas sobre os quais vamos refletir nesse trabalho.

\section{Pasárgada e Quinta Lebrão: diferentes contextos}

A literatura sociojurídica das décadas de 70/80 consagrou a pesquisa de Boaventura de Souza Santos (1988) e sua análise sobre a associação de moradores da favela do Jacarezinho. No estudo de Santos a associação de moradores assumiu funções normativas e judiciais perante a favela, desenvolvendo um conjunto de práticas jurídicas à margem do Direito estatal. A explicação para a produção normativa institucionalizada na associação teve como concepção de base a condição de subintegração em que se encontravam os moradores da favela e a necessidade de espaços de mediação dos conflitos surgidos na comunidade. Assim, a associação de moradores, por gozar da legitimidade necessária ao exercício do poder, mesmo sem o monopólio da violência, ainda que portadora de uma violência simbólica potencial, tornou-se o espaço privilegiado para a mediação dos conflitos dos moradores da favela. Os mecanismos de legitimação eram os típicos da década, ou seja, pressupunham a representação política de ideais e especialmente dos interesses da comunidade.

A favela observada por Boaventura de Souza Santos (1988) sobrevivia num duro contexto de ausência de serviços estatais básicos, como: água, esgoto, rede elétrica, pavimentação e ainda sob a ameaça iminente de remoção. Diante das péssimas condições de habitabilidade, os moradores organizavam-se com o intuito de melhorar a estrutura coletiva, criando redes coletivas de água, eletricidade e onerando, consequentemente, qualquer iniciativa política estatal que visasse a remoção (idem). O início da década de 70, período observado por Sousa Santos (1988), corresponde a fronteira entre dois momentos distintos na história das organizações de favelas no Rio de janeiro. Até então as políticas governamentais intercalavam-se entre a remoção da favela e sua urbanização, não havendo opiniões majoritárias na gestão pública sobre qual a melhor forma de lidar com as favelas da cidade. A remoção foi uma realidade para 100 mil pessoas entre os anos 1968 e 1975 (Burgos, 2000), famílias foram obrigadas a desfazer grande parte de seus laços societais e deslocaram-se, em sua maioria, para espaços geográficos distantes de seus locais de trabalho. No entanto, a década de 70 assiste a uma recuperação dos movimentos das favelas, tendo como marco o III Congresso de Favelados do Estado da Guanabara em 1972 que reafirmou a luta contra a 
remoção e pela urbanização das favelas, constrangendo o regime militar que recentemente havia promovido a cassação de lideranças da FAFEG (Federação das associações de favelas do estado das Guanabara) e contribuindo consequentemente para o aumento do custo político das remoções (idem).

O contexto da pesquisa de Sousa Santos (1988) é o da transição, pois se a FAFEG ainda suspirava não representa mais uma identidade constituída a partir das resistências às remoções, em especial na década de 50 quando o discurso das lideranças adquiriu teor político-ideológico. Foram diversas as intervenções estatais no movimento de favelados desde 1945 (data da primeira organização de moradores de favelas) até a derradeira ação da ditadura militar que desarticulou a independência das associações de moradores e as transformou, por via de decreto (Dec. número 3330/68), em aparelhos do Estado. Antes da ditadura as tentativas de cooptação de lideranças ou mesmo a formação de lideranças pela Igreja e Estado haviam tentado subordinar a independência das associações, mas foi a ditadura quem consolidou a subordinação das lideranças, fazendo do início dos anos 70 a fronteira entre o fim da explícita intervenção do Estado nas favelas, já livres das lideranças indesejáveis e o vazio das políticas que se sucederam até as primeiras eleições livres da década de 80 (Burgos, 2000).

A prática política das associações de moradores, a partir da primeira metade dos anos 70, como defende Burgos, orbitou entre o ressentimento gerado pelo terrorismo das políticas de remoção e o clientelismo político. O ressentimento provocou um distanciamento da vida das favelas em relação à política da cidade, provocando uma carência de legitimidade do poder público e das próprias associações que em muitos lugares eram confundidas com o próprio Estado. O clientelismo provocou a acomodação pragmática das lutas por direitos, transformando-as em disputa por favores (idem). A favela estudada por Santos situava-se exatamente neste complexo contexto de início do fim das intervenções violentas do Estado o que favorecia, por um lado, a rearticulação das associações de moradores e por outro sua desnecessidade num quadro de fim iminente das remoções. A associação observada por Santos possuía vida e gozava de legitimidade perante os moradores, indicando que o ressentimento não foi o sentimento majoritário de seus associados em relação à associação, mas representou provavelmente o distanciamento das políticas da cidade e gestou o segundo caso dos tipos apresentados por Burgos, ou seja, o clientelismo, mesmo que de forma embrionária. Em Pasárgada, no relato de Santos, não se questionava o Estado nem a ideologia 
dominante, assim como não se lutava por direitos, apenas adaptava-se as concepções dominantes à realidade dos interesses dos moradores.

O associativismo descrito por Santos centrou-se na defesa da moradia e sua salubridade, tornando a Associação de Moradores esfera legal de representação dos interesses coletivos perante a estrutura estatal. Legitimada ou não por seus moradores, a Associação de Moradores tornou-se interlocutor político da favela com órgãos estatais e, como observou Boaventura Santos (1988), passou a absorver funções típicas do Estado Moderno, como a prestação jurisdicional. O reconhecimento da situação de irregularidade perante a lei provocou nos moradores o reconhecimento do poder coercitivo do Estado como um risco aos seus interesses, dentre eles o da remoção ${ }^{1}$. Sem poder contar com o poder oficial, caberia aos moradores a criação de espaços de solução de conflitos que não pusessem em risco sua sobrevivência coletiva. Assim, a associação de moradores tornou-se o espaço para solução dos conflitos internos da comunidade e sua representante face ao Estado brasileiro ${ }^{2}$.

A prestação jurisdicional extra-oficial, em nome da segurança das relações jurídicas extra-oficiais, associa-se à função cartorial de registro dos negócios realizados no interior da comunidade, assim a compra e venda, locação e outros negócios de Direitos reais eram registrados na associação de forma homóloga aos negócios jurídicos realizados no asfalto. A homologia com o Direito do asfalto garante, inclusive, a absorção vulgar de institutos jurídicos do Direito oficial, desde que não colocassem em risco a própria existência comunitária, assim, por exemplo, o direito à propriedade é reconhecido em Pasárgada, mas por propriedade de moradores compreender-se-ia ocupações ilegais, face ao Direito estatal (Santos, 1988).

A legitimidade das decisões jurídicas proferidas em Pasárgada, pela associação de moradores era garantida pelo processo retórico-argumentativo desenvolvido em procedimentos homólogos aos de um processo judicial, porém assentava-se a decisão do presidente da associação de moradores não na aplicação de normas gerais e abstratas, mas sim nos argumentos das testemunhas ou mesmo dos ausentes conhecedores do caso capazes de provocar o assentimento e persuasão dos moradores em litígio. Se a persuasão à uma das

\footnotetext{
${ }^{1}$ Pode-se intuir que a participação se dava por interesses básicos e coletivos de sobrevivência e não por uma ideologia participativa presente na comunidade, pois com a Constituição de 1988 e seus aspectos sociais que retiraram em grande parte a ameaça de remoção às associações entraram em declínio.

${ }^{2}$ A associação como órgão de representação dos moradores perante ao Estado, antes de ser uma construção totalmente espontânea dos moradores foi também consequiência de um conjunto de ações do Estado brasileiro no sentido de adequar as lideranças faveladas aos interesses do Estado.
} 
partes fosse fracassada e os argumentos oferecidos não satisfizessem a todos, o discurso da decisão deveria ser suficiente para estigmatizar aqueles que se conduzissem de forma diversa prescrita pela decisão (idem).

É possível observar-se que em Pasárgada a Associação de moradores coloca-se como instrumento central na articulação entre o binômio direito-política e os moradores. No caso do Direito, a inexistência de uma ordem jurídica que protegesse aos interesses dos moradores tornou tal Direito inapto para a solução de conflitos e preservação da comunidade, fazendo com que a associação desenvolvesse um espaço para solução de conflitos e registro de contratos e sonhos. O procedimento adotado na associação exerce papel fundamental no reconhecimento da legitimidade da associação, pois quando há a preocupação, por falta de instrumentos coercitivos, em buscar a mediação dos conflitos há um contínuo processo de legitimação da associação como espaço comprometido com os interesses da coletividade. A decisão que persuade a comunidade traduz-se no convencimento de que a Associação de moradores é um espaço comunitário que a mantém distante do risco estatal e estabelece uma estabilidade no convívio rotineiro. Assim, o Direito de Pasárgada, ou melhor, da associação de moradores é um forte instrumento de legitimação de si mesma.

É possível observar, através de Pasárgada, que os laços fundamentais entre os moradores se encontram em uma esfera instrumental, ou seja, encontram-se unidos pelo infortúnio da miséria da qual até o Estado deseja despojá-los e marginalizá-los ainda mais. É a associação o espaço seguro para a defesa da existência da favela e dos interesses coletivos da comunidade. O discurso político, antes de ideológico, é qualquer um que defenda a sobrevivência da favela e dos modos de convivência convencionados pelos moradores. Assim, a associação de moradores pode legitimar-se por suas ações no Direito e usar tal capital para conexão com o poder político que encontra a associação como pessoa jurídico-política que representa um conjunto de proto-cidadãos. A conexão entre sistema político e associação de moradores se intensifica com os processos eleitorais no Brasil, tornando a favela um celeiro de eleitores e a associação de moradores seu possível capataz. A legitimidade da associação de moradores é também alimentada pelas relações entre os seus dirigentes e lideranças políticas capazes de atender anseios imediatos por serviços públicos no interior da favela ou nos seus arredores. É nesta outra relação com a política que a associação de moradores irá alimentar sua legitimidade e construir a força necessária para constituir-se como importante ator político nas décadas de 70/80. 
O Brasil e as relações político-sociais alteraram-se de forma intensa nos últimos trinta anos, alcançou-se a democracia, partidos representativos de ideologias censuradas constituíram-se, prefeitos, governadores e presidentes foram eleitos, ou seja, o sistema político brasileiro foi remodelado e formatado segundo o modelo democrático ocidental. A sociedade transformou-se e reorganizou-se politicamente, buscando cada vez mais a identidade com temas transversais que não dependiam da contestação do modelo político, como: meio ambiente, raça, gênero. O modelo de organização política em torno das associações de moradores entra em declínio na década de 80, tornando, na primeira década do século XXI, as associações remanescentes frágeis e desprovidas da legitimidade observada por Souza Santos (1988). Muitas são as causas do declínio tais como o aparelhamento das associações por partidos políticos, fazendo de muitas um bureau político de interesses eleitorais; a descrença no modelo político representativo e nas próprias associações, as políticas sociais que concederam paternalisticamente direitos aos moradores de favelas, ou seja, há um complexo de causas que convergiram contribuindo para o declínio dos movimentos associativos em favelas.

A partir de 1982, com a eleição de Leonel Brizola para o governo do Estado do Rio de Janeiro, as políticas destinadas às populações faveladas do Estado fluminense alteram-se drasticamente, no lugar da intervenção violenta, com auxílio da estrutura repressiva do Estado ou da omissão, inaugura-se a intervenção através de projetos de inclusão social ${ }^{3}$. No verso da política brizolista, lideranças foram cooptadas e restabeleceu-se o vínculo clientelista em moldes paternalísticos, quando os políticos da rede clientelista foram eliminados, estabelecendo-se um vínculo direto com o governador e seu secretariado. É certo que tal prática política, mesmo que imbuída de valores democráticos, contribuiu para acentuar a relação histórica existente entre as associações de favelas com o poder estatal, ou seja, acentuou a identificação das associações como agente do Estado, prestando um desserviço a independência e autonomia das associações de moradores (Burgos, 2000).

Na década de 80, durante o processo de redemocratização que resulta na Constituição de 1988, a dinâmica das associações de moradores não é alterada de forma relevante, havendo apenas um aprofundamento das relações das associações com o Estado e a formação de lideranças da própria comunidade para a substituição de alguns dos antigos políticos que

\footnotetext{
${ }^{3}$ Dentre os programas sociais desenvolvidos o proface da CEDAE levou sistemas de água e esgoto a 60 favelas do Estado. (Burgos, 2000; P. 42)
} 
intermediavam as relações do Estado com a favela. Assim, lideranças comunitárias transformam-se em candidatos e, face ao sistema eleitoral brasileiro, passaram a arrecadar votos para legendas diversas - fenômeno que se intensifica na década de 90. Durante os anos 80 a bandeira dos direitos sociais é tema relevante, mas não mais de uma associação articulada e representativa de ideais políticos, mas sim na vertente paternalista, tornando-se a conquista dos direitos sociais fruto mais de uma concessão aos excluídos que propriamente uma conquista da luta destes segmentos. A percepção dos direitos sociais é de que eles deveriam existir independente da vigilância dos próprios beneficiários, assim não seriam propriamente uma conquista, mas um reconhecimento de que os hipossuficientes tinham direitos sociais. Desta forma, os direitos sociais são dados sem uma consolidação dos direitos civis e políticos, desprezados e transformados em moeda de troca no ambiente clientelista.

É nos primeiros anos do século XXI que encontramos a Quinta Lebrão caudatária do processo histórico descrito acima. Ou seja, uma associação de moradores frágil de fraca representatividade na comunidade e com dificuldades para renovação de quadros. As lutas contra a remoção não mais faziam sentido, assim como o reconhecimento por direitos sociais. Os sonhos da casa própria e de uma boa qualidade de vida, apesar de alguns avanços das condições sanitárias da favela, não chegaram e o que chegou foi fruto de uma negociação com lideranças políticas para concretização de direitos sociais em troca de votos. Assim, não havia a necessidade da participação política como forma de garantir e conquistar direitos bastava a troca por votos.

A novidade da primeira década do século XXI é a relação da associação com o Direito, pois se em Pasárgada a associação de moradores criava direito e produzia decisões jurídicas para a comunidade, em Quinta Lebrão a associação de moradores estabelece uma relação de mediador entre o Direito estatal e a comunidade, indicando advogados e informando aos moradores sobre os possíveis acessos às instituições de assessoria jurídica popular. A associação de moradores, findado o temor do Estado, não é procurada para a mediação dos conflitos comunitários dos moradores que vêem sua entidade representativa como o espaço destinado à solicitação de "favores jurídicos". Os moradores de Quinta Lebrão, diante da dificuldade de acesso a instituições que promovam assessoria jurídica, buscam nas relações e ligações políticas da associação de moradores o acesso à técnicos capazes de representá-los no interior do sistema jurídico. Assim, os moradores renunciam a um direito alternativo ao do Estado e reconhecem a ordem jurídica estatal, não subsistindo, 
portanto, em Quinta Lebrão uma das fontes de legitimação da associação de moradores de Pasárgada.

Ao lado do acesso à Justiça a associação de moradores de Quinta Lebrão promove a intermediação entre os interesses da comunidade e o poder executivo, capitaneando a rede paternal estabelecida com políticos locais e, muitas vezes, gerenciando uma rede clientelista. Os moradores de Quinta Lebrão sabem que possuem direitos, mas não se organizam para exigi-los, esperando da associação ações que os concretizem. A cobrança por melhorias na qualidade da vida comunitária recai, quase sempre, sobre a associação que, como um órgão estatal, teria a obrigação de concretizá-los. O contexto de Quinta Lebrão diferencia-se do descrito por Santos, onde os moradores organizavam-se para a melhoria de seu ambiente. Em Quinta Lebrão os moradores reconhecem seus direitos (que inexistiam em Pasárgada), não havendo, assim, para o morador, a necessidade de ação, pois a responsabilidade seria estatal e não dos cidadãos habitantes da favela que simplesmente cobram da associação a concretização de seus direitos. A identificação da associação de moradores com um bureau do Estado, tanto em Quinta Lebrão como em Pasárgada, pode ser explicada pelo papel que estas desenvolveram durante décadas de intermediadores legais dos moradores, tanto pela prática clientelista como pelo paternalismo, cujas práticas contínuas esvaziaram a associação de moradores de legitimidade, presente ainda apenas nas tênues relações com o poder local.

A observação de Quinta Lebrão é sintomática da relação existente entre as populações excluídas e os direitos sociais. Se por um lado a Constituição de 1988 consolidou diversos direitos para a proteção da população mais carente, mesmo sem sua efetiva concretização, a recepção de tais direitos parece ter sido compreendida não como fruto de uma conquista, mas de uma doação, ou seja, os moradores das favelas que um dia suplicaram por direitos agora devem requerer a concretização de tais direitos e para tanto o Judiciário torna-se uma das principais portas de entrada de tais requerimentos, provocando, ainda mais, o esvaziamento das organizações políticas da sociedade que se submetem constantemente ao arbítrio do judiciário, abdicando de uma posição ativa na política brasileira. A observação de campo acaba por indicar a necessidade de um aprofundamento nos estudos mais recentes sobre a judicialização da política, sobre o associativismo do brasileiro e, em especial, sobre a cidadania, temas que devem oferecer subsídios mais consistentes para a análise das relações políticas e sociais com o sistema jurídico. 


\section{A Igreja e a Associação}

A favela de Quinta Lebrão, no contexto excludente que marca a sua situação social como grupo e espaço de relações, conta com duas instituições sociais que dão tom e ritmo às suas relações sociais internas. Essas instituições funcionam de diferentes formas, mas de maneira sutilmente intercalada, possuindo, não apenas, força social de ordenação das relações internas, mas principalmente cumprindo a função de mediação entre a comunidade e sociedade. Assim, tanto a associação de moradores como a da Igreja Evangélica se pautam pela situação social de exclusão, respondendo, sem questionar a ordem excludente, de formas distintas à busca por canais políticos, jurídicos e simbólicos de integração.

No caso da associação de moradores há um sistema de mediação entre a comunidade e o poder público através de dois canais: (1) dos agentes do poder, ou seja, vereadores, prefeito, lideranças partidárias que incorporam, através de esquemas clientelistas, lideranças locais na vida política da cidade e (2) do sistema jurídico estatal, através intermediação pela associação, muitas vezes dependente de relações pessoais e não raras vezes amarrada a agentes do poder, entre a população e operadores profissionais do direito, como advogados e defensoria pública, tornando a associação de moradores uma prestadora indireta de serviços jurídicos.

De outro lado, temos as Igrejas Evangélicas que executam um trabalho de ordenação moral e simbólica da comunidade. Assim como nas grandes metrópoles e centros urbanos do país, a figura do pobre se confunde com a do bandido, do vagabundo, do meliante e tantas outras definições e categorias de acusação que compõem um sistema de classificação que reconstrói nas classes populares as fronteiras e os marcos que separam a "ordem" da "desordem", ou seja, o "vagabundo", o "bandido", o "meliante" do pai de família, do trabalhador, figuras da respeitável e santificada pobreza, ou seja, o humilde ${ }^{4}$.

É através da religiosidade que a ordem social é reconstruída simbolicamente numa reinterpretação de normas e valores da moralidade cristã, redefinindo a posição social do evangélico, não como pobre, favelado, excluído e explorado, mas como "irmão", um membro do "povo de Deus". É através dessa moralidade cristã que a Igreja Evangélica constrói sua

\footnotetext{
${ }^{4}$ O próprio crente escreve na sua imagem, na sua apresentação social as marcas distintivas desta oposição, usam ternos pobres e surrados, andam com a bíblia debaixo do braço, cortes de cabelo discretos. Não raras vezes podem ser vistos em companhia de suas esposas ou noivas andando sobriamente de braços dados, elas usando
} 
base ética na comunidade, realizando a mediação simbólica entre a comunidade e a sociedade. A base ética do discurso evangélico é a fonte legitimadora da Igreja Evangélica para intervir na vida pessoal de seus fiéis e na mediação normativa de conflitos familiares, operando conciliações e concertando situações que, de outra forma, iriam ser encaminhados ao Poder Judiciário. Há um direito religioso que opera por mores e tópicos do discurso bíblico, transformando o pastor, através de seu discurso persuasivo, em juiz conciliador ${ }^{5}$.

3. A Igreja Evangélica: a ordenação religiosa da conduta de vida e a normatividade de inclusão na ordem.

Pensar a religiosidade e suas relações com a ordem social significa, como sugere Pierre Bourdieu (1992), ligar uma ordem simbólica à uma ordem de relações sociais objetivas. Assim, as relações de classe e de dominação, em que uma determinada ordem simbólica, cumpre duas funções: (1) legitimar aos dominantes sua posição social e (2) compensar aos dominados sua posição desfavorável. Nesse sentido, dois tipos de religiosidade se intercalariam e se contraporiam: a religiosidade do dominante e a do dominado ${ }^{6}$. Assim, pensar o papel normativo e integrador das Igrejas Evangélicas em Quinta Lebrão significa pensar tais instituições como elementos de um complexo jogo simbólico de significações, classificações e normatizações que atribuem sentido ao conjunto normativo que regula a conduta dos fiéis, proporcionando aos crentes um sentido na relação entre "ordem" e "desordem". As Igrejas propiciam, também, a formação de um habitus específico entre seus fiéis, diferenciando-os do resto da comunidade.

Como em outras comunidades desse tipo, Quinta Lebrão também possui, em grande parte de sua população, indivíduos que abandonaram suas crenças em religiões afro-

vestidos longos e sóbrios, cabelos compridos e o rosto de ambos sempre exibindo aquela típica fisionomia séria de quem vive de acordo com a vontade de Deus.

${ }^{5}$ As lideranças religiosas, em especial os pastores, podem estabelecer-se, ainda, através de partidos políticos, como lideranças políticas. Esta forma de participação político-religiosa não é recente e nem é específica da localidade em questão, como apontam os estudos de Reginaldo Prandi e Flávio Pierucci (1996), proporcionando, então, aos fiéis posições de destaque junto à associação de moradores e constituindo uma ligação entre os dois espaços sociais.

${ }^{6}$ As mensagens religiosas buscam criar um sentido e um significado para o mundo social e natural, explicandoos como reflexos de uma teodiceia ou de uma ordem cósmica sobrenatural. De outro lado, as religiosidades participam da construção normativa simbólica da ordem a que se referem, construindo fronteiras simbólicas entre o bem e o mal, entre aquilo que é da vontade de Deus e aquilo que é maldade. Assim, tanto as posições sociais dos sacerdotes quanto a dos leigos estarão fortemente relacionadas com a estrutura objetiva de posições de classe e dominação (Bourdieu, 1992). 
brasileiras para aderir ao credo evangélico ${ }^{7}$. Esse fenômeno de conversão religiosa implica em significativa mudança simbólica, propiciando a reinterpretação do lugar e do espaço social em que a comunidade está situada, isto é, novos sentidos para o conjunto de relações sociais objetivas em que a comunidade se situa, alterando as categorias de percepção e avaliação dos membros dessa comunidade e atualizando o habitus do convertido. A religiosidade evangélica, distintamente da religiosidade afro-brasileira ${ }^{8}$, envolve uma ética clara em relação às condutas de vida, uma negação clara ao mundo social que valoriza a subjetividade do fiel até a sua anulação colocando-o fortemente vinculado a sua comunidade religiosa. A moralidade cristã levada às últimas conseqüências acaba por estabelecer uma fronteira entre a comunidade religiosa e o restante do mundo social, opondo o "povo de Deus" ao território do diabo. Assim, a ética evangélica também se configurará como missionária, destinando ao fiel e ao sacerdote a tarefa de evangelizar a sociedade. É a partir da chamada teologia da prosperidade que notamos as coordenadas dessa fronteira simbólica entre "o povo de Deus" e o mundo social, pois tal teologia não santifica e nem valoriza a pobreza, pelo contrário, esta é vista como obra do demônio que vem acompanhada de outras de suas obras como a violência doméstica, a criminalidade, o tráfico de drogas e todos problemas sociais e psicológicos que, no imaginário social, estão ligados às comunidades de baixa renda como resultado da pobreza. Assim, a problemática sai dos quadros de referência de uma questão social e ganha outro significado simbólico na esfera da religiosidade, redefinindo a dicotomia entre "ordem", e "desordem" nos termos de uma ordem divina em oposição a uma desordem transgressora a ser combatida. Desta forma, a caracterização do "povo de Deus" se dá pela conduta reta dentro dos estreitos mores cristãos, como: valorização da família, do casamento, da honestidade e do trabalho responsável ${ }^{910}$. É justamente a partir dos mores e dos sentidos elaborados pela fé

\footnotetext{
7 Não dispomos de dados estatísticos que nos mostrem a envergadura deste processo, mas segundo os informantes da pesquisa de campo, esta mudança religiosa se deu ao longo da década de 80 e se acentuou na década de 90, momento de avanço das seitas evangélicas em todo país (Prandi\&Pierucci, 1996).

${ }^{8}$ Como têm demonstrado os estudos de Prandi \& Pierucci (1996), a religiosidade afro-brasileira se marca pela ausência ética, ou pelo menos por uma tolerância no que concerne às condutas de vida. O fiel se liga ao mundo não por uma negação do mesmo, mas por uma aceitação de sua realidade. De outro lado, também busca operar nesse mundo sem transformá-lo, mas sim buscando tirar vantagens dele. Daí que a magia e o pensamento mágico cumprem um papel fundamental nesse tipo de religiosidade, pois se busca uma manipulação simbólica que envolve certa racionalidade pragmática. Seus deveres e obrigações são para com o seu orixá e para com o terreiro ao qual está ligado. Isso tudo implica num certo individualismo e, de outro lado, num sistema de troca com a divindade. Como afirmam Prandi \& Pierucci (1996), tal religiosidade não estimula a participação política.

9 Dentre esses valores, a família figura no topo da hierarquia e acaba funcionando como um marco, uma fronteira entre a "ordem" e a "desordem", isto é, funciona como critério de diferenciação entre aqueles que estruturam suas famílias de acordo com o modelo patriarcal cristão e aqueles que, fugindo desse modelo, teriam famílias desestruturadas. Assim, o avanço das seitas evangélicas significou outro tipo de ordenação e outra forma
} 
evangélica que a igreja consegue se tornar um lugar de ordenação social e de formação de um habitus, sendo capaz de estabelecer uma normatividade para regular as condutas de vida de seus fiéis.

O que observamos em Quinta Lebrão não é um fenômeno que discrepa do observado em outras comunidades como as do Rio de Janeiro e São Paulo. No caso estudado por Marcelo Lacombe (1999) na favela Jardim Icaraí na periferia da capital paulista foi observado o mesmo processo em que as famílias faveladas se reorganizavam em função de uma outra normatividade ética ${ }^{11}$. É justamente nessa reorganização da comunidade doméstica, em que os problemas familiares como a violência e o alcoolismo vão sendo supostamente superados, que reside o coração da normatividade evangélica na comunidade. É em torno desses problemas que vai girar o conjunto dos litígios para os quais os pastores serão chamados para resolver e arbitrar. Identificamos, então, uma diferença entre o uso jurídico da associação de moradores e o das Igrejas Evangélicas, pois em Quinta Lebrão, a busca pela associação de moradores para resolver um litígio confunde-se com a procura de favores jurídicos, de um advogado, já a busca pelo Pastor é a tentativa de encontro de um juiz.

Em Quinta Lebrão ${ }^{12}$, como na Pasárgada de Boaventura de Souza Santos (1988), usa-se a retórica no processo de mediação dos conflitos, sendo em Quinta Lebrão, competente para o exercício do papel de juiz-conciliador, o pastor que buscará, através de apelos à ordem que pauta as relações da comunidade religiosa, persuadir os fiéis litigantes. A supervisão da conduta dos fiéis pelo sacerdote e o uso da retórica marcam a relação do líder religioso com:

de lidar com o mundo social mais amplo em relação às comunidades de baixa renda, essa atualização do habitus que o reconfigura no processo de conversão religiosa, provoca profundas mudanças de comportamento.

10 A primeira vista poderíamos supor que se trata aí de um processo de racionalização da conduta e do pensamento religioso, uma passagem do pensamento mágico para uma religiosidade ética e de salvação. Porém, essa fórmula simples (Prandi \& Pierucci, 1996) não se mostra no caso de Quinta Lebrão e nem em outros casos. Isto porque as denominações pentecostais e neopentecostais acabam, na forma litúrgica reintroduzindo a magia de outra forma: milagre, graça divina na fusão com o Espírito Santo e até mesmo pacto com divindade são elementos de pensamento mágico que marcam o imaginário evangélico, além das divindades das religiões afrobrasileiras que ali reaparecem como manifestações do demônio. É aí que o mundo se reencanta e se transfigura numa realidade habitada por Deus e por demônios e é aí onde é possível para o fiel reencontrar sentido para sua existência e para próprio mundo social.

${ }^{11}$ No Jardim Icaraí, como em Quinta Lebrão, a reordenação traz como conseqüência não apenas a manutenção da comunidade doméstica, mas a tornava mais eficiente como mecanismo de sobrevivência, isto é, facilitava a inserção do chefe de família ao mercado de trabalho e re-montava as relações familiares dentro dos mores da ética cristã. Tal efeito, no entanto, estabelecia um modelo de vida familiar ainda centrado na figura do chefe provedor reforçando-lhe a autoridade, mas também lhe atribuindo os deveres tradicionais da responsabilidade pelo bem estar da comunidade doméstica.

${ }^{12}$ As ações dos pastores de Quinta Lebrão não se fundam em normas jurídico-estatais abstratas e gerais, assim como não se dão por procedimentos formalizados, mas sim a partir do senso de justiça constituído no diálogo entre as partes envolvidas no litígio e fundados nos valores cristãos.

Revista de Sociologia, Antropologia e Cultura Jurídica | e-ISSN: 2526-0251 | Encontro Virtual | v. 7 | n. 2 | p. 18 - 37 | Jul/Dez. 2021. 
(1) a associação religiosa e a (2) comunidade de Quinta Lebrão ${ }^{13}$. Ao primeiro espaço correspondem as obrigações de conduta de vida e participação na vida orgânica da Igreja, cuidando do templo, tocando na banda de música gospel ou assessorando o pastor no seu trabalho missionário. No segundo espaço cobra-se do fiel conduta de vida exemplar ${ }^{14}$. Assim, a igreja participa, de forma ativa, na busca por soluções aos problemas sociais da comunidade de Quinta Lebrão ${ }^{15}$.

Se a atuação evangélica é marcada por uma recusa do mundo social, o evangélico, por sua vez, irá recusar este mundo social, atuando como missionário, isto é, evangelizando o mundo. Não à toa, o tema das missões é profundamente tocado nos cultos numa forte linguagem ritual, esta sim capaz de inculcar com eficiência a missão como um dever que cabe ao fiel e ao pastor. Esta é uma guerra de posições em que os combatentes se vêem como catequistas na luta contra "as forças do mau". Daí que o clientelismo e a lógica do favor ganham uma força renovada na semântica política evangélica, pois esta postula a primazia dos

${ }^{13}$ Essa distinção é aqui importante, pois aos membros efetivos da associação religiosa é dado um conjunto de obrigações que aqueles que não são membros efetivos estão isentos.

${ }^{14}$ No entanto, os momentos de culto e o acesso ao Pastor são abertos a todos, membros ou não membros. Assim, há toda uma política em relação aos não membros que implica na supervisão mais branda de suas vidas e na persuasão, visando a sua conversão. Este é o caso de uma moça entrevistada que sendo freqüentadora assídua dos cultos não era membro da Igreja, pois ainda não havia se casado com companheiro com quem já vivia há alguns anos. Indagada sobre a sua conversão a informante nos relatou que só poderia se converter se se casasse com o companheiro. Perguntada por que não o fazia, respondeu que não tinha dinheiro para pagar o casamento civil, requisito para o casamento religioso. Porém, de acordo com outra informante que ali estava presente, a própria igreja arcaria com os custos de um casamento civil para a realização do casamento religioso. Assim, a primeira informante revelou que não tinha intenção de se casar com o seu companheiro. Porém, de acordo com a entrevista do Pastor, a Igreja costuma realizar casamentos gratuitos para os casais que não podem pagar pela cerimônia, independente de serem membros ou não da Igreja, o que significa um serviço simbólico gratuito para a população de baixa renda. Se a relação do Pastor com os membros leigos da associação se dá por uma supervisão de suas condutas de vida, a relação com os não membros é marcada por uma supervisão mais tolerante.

${ }^{15}$ Um deles é o problema dos jovens com o uso de drogas e das adolescentes grávidas, o que implica uma política de atuação especial para a juventude, com a organização de suas bandas de música com os que são membros, aconselhamentos especiais e até distribuição de preservativos para os que não são membros da associação. Perguntado sobre este último item, o Pastor nos respondeu que não podia se defrontar com uma situação alarmante sem tomar alguma providência, mas esta só podia ser feita em relação aos jovens não membros. Aqueles que já haviam sido batizados deveriam seguir as normas rígidas da moralidade sexual cristã e já estariam plenamente convencidos da validade dessas normas. Contudo, o objetivo das políticas em relação aos jovens não membros da associação é o de torná-los membros efetivos e participantes, e assim poder supervisioná-los mais de perto. Muitas igrejas evangélicas das comunidades de baixa renda têm se mostrado um espaço alternativo para a participação política dessas camadas da população. Este não é um fenômeno nem recente e nem restrito à Quinta Lebrão como mostram os estudos de Prandi\&Pierucci (1996). Assim, o Pastor que entrevistamos já fora candidato a vereador por um partido político de grande porte e de orientação política de centro-esquerda. Também, as lideranças da associação de moradores entrevistadas mostraram uma adesão forte e militante às denominações evangélicas o que repõe na sua moralidade e na sua conduta política um acento positivo sobre a atuação assistencialista em detrimento da atuação política mais tradicional, de novo a mesma oposição da qual já falamos que opõem o político ao líder comunitário e a ética de responsabilidade weberiana à ética da convicção que prescreve a atuação caridosa no mundo.

Revista de Sociologia, Antropologia e Cultura Jurídica | e-ISSN: 2526-0251 | Encontro Virtual | 
valores pessoais e subjetivos contra as normas impessoais e objetivas do contrato. Teríamos em Quinta Lebrão o protestantismo sem espírito para um capitalismo sem ética? O que há em Quinta Lebrão é um mecanismo de adequação à "ordem" e um sistema precário de inclusão social, aparentemente sem qualquer força social apta a se constituir em via para a modernidade, como identificou Weber (2004) no protestantismo calvinista ${ }^{16}$.

Como mecanismo de inclusão social, o processo que aqui salientamos, segundo a lógica simbólica dos jogos de distinção (Bourdieu, 1992) é precário, pois a própria "ordem" simbólica das classes dominantes classifica a atuação e a religiosidade do evangélico como uma manifestação patética das classes populares, enxergando-as como vítimas ingênuas do charlatanismo e dos maus entendidos religiosos. A precariedade desta inclusão social se dá também pela renovação da força social e simbólica das estruturas sociais do atraso, como a valorização das relações pessoais e a cultura do favor que funcionam como mecanismos de exclusão social porque são obstáculos à universalização de direitos e deveres. Tal situação aponta também para uma crise da atividade política propriamente dita na oposição entre o líder comunitário cristão e o político laico.

\section{Considerações Finais: Fé, Política e Justiça}

As ambigüidades normativas que montam o quadro de referências da comunidade de Quinta Lebrão podem ser analisadas dentro do trinômio fé, justiça e política, cada um definido de maneira intercalada com o outro. Fé, figurando como um valor que norteia a consciência moral da comunidade se contrapõe ao elemento da política, este último desvalorizado por estar marcado como representante do mundo dos interesses e da corrupção redimível apenas com a aplicação da justiça, isto é, com o conjunto de valores que deveriam se realizar. Daí que a figura do líder comunitário cristão se sobrepõe à figura da liderança política, a primeira carregada dos valores da fé torna o líder comunitário apto a realizar as exigências da justiça. Esta oposição marca um quadro mais amplo de uma crise da própria política, enquanto atividade capaz de, assim como a religião, produzir esperança numa vida melhor. Como definia Weber $(1982 ; 1991)$ em sua teoria do carisma, mobilizada tanto para uma sociologia da religião quanto para uma sociologia política, o líder carismático, seja ele o

\footnotetext{
16 Como salientaram Prandi\&Pierucci (1996) o protestantismo evangélico acentua tanto a subjetividade como um valor que acaba por anulá-la com a constituição da sua associação religiosa capaz de supervisionar a conduta de vida de seus membros.
} 
político, ou o profeta religioso, se marca pela capacidade de mobilizar as pessoas em função da esperança numa vida melhor. Desta forma, a dominação propriamente carismática é aquela capaz de romper com as referências das dominações rotineiras da racionalidade legal e da tradição. No entanto, a diferença entre política e religião que, no contexto de um mundo racionalizado e secularizado, se expressa em duas éticas distintas, a ética responsabilidade e a da convicção, pressupõe a diferenciação entre as esferas de valor, isto é, os valores políticos não serão confundidos com os valores religiosos, proporcionando à política a capacidade de produzir todo um conjunto próprio valores e crenças, como o socialismo, o liberalismo e o comunismo, sendo a opção religiosa relativamente irrelevante. De outro lado, embora haja por parte do clero, enquanto produtor de um sistema simbólico, a tarefa de legitimar ou opor-se a ordem social, a ética religiosa que busca a salvação da alma se opõe frontalmente às exigências de ética da responsabilidade imposta e necessária à atuação política racionalizada e pautada pelo ideal do bem público e coletivo (idem). Assim, temos não apenas dois sistemas éticos contrapostos, mas, derivados deles, duas noções de justiça. Uma delas, a da fé, é a justiça pautada pelos mores e valores cristãos da caridade, dos bons costumes, da família. De outra forma a justiça ligada aos valores cívicos da idéia de bem público e do interesse bem compreendido, como a capacidade de ligar o interesse particular ao interesse coletivo (Tocqueville, 1977).

O que encontramos em Quinta Lebrão foi uma situação de contradição entre uma moralidade laica e outra religiosa. Esta contradição, no entanto, está ela mesma, permeada das ambigüidades da cultura normativa brasileira de que falamos acima, isto é, embora exista em Quinta Lebrão um vasto campo de atuação política, o caráter propriamente político da atuação é denegado em função da idéia de dom e vocação, fazendo aparecer a vontade política não politizada da realização dos direitos sociais, políticos e civis que marcam o moderno projeto democrático do país e que leva essa vontade a uma fácil adesão ao clientelismo, à troca de favores. Isso porque o agente desta vontade política a traduz num outro senso de justiça, o senso religioso que põe um acento positivo nas relações pessoais e subjetivas.

É nesses termos que funcionam os complexos mecanismos de mediação que articulam na comunidade a associação de moradores e as Igrejas Evangélicas como mediadores entre a comunidade e o mundo social mais amplo representado pelo Estado e seu aparato jurídico e político. A conciliação na igreja segue a pauta dos valores cristãos da conciliação, ao passo que na associação de moradores, através da prestação de favores 
jurídicos, realiza-se a justiça laica, guiada pelas normas e valores consagrados pelo Estado. Assim, o Estado não é apenas visto como uma instituição em referência a qual se lutaria pela criação de direitos novos ou pela realização de determinadas políticas públicas, mas como um prestador de serviços capaz de fazer valer os direitos para cada indivíduo que o procure. As demandas do cidadão não são formuladas coletivamente no movimento político, mas sim de forma individual e muitas vezes pela petição judicial ${ }^{17}$. Na relação individual com o Estado que, no caso de Quinta Lebrão, passa pela mediação pessoal das lideranças da associação de moradores, em grande parte evangélicas, reconhece-se o Estado apenas um prestador de serviços, legitimando, aos olhos das classes populares, o assistencialismo da vontade política despolitizada. Neste contexto e com a denegação do mundo dos interesses operada pela Igreja, a associação de moradores acaba funcionando como um aparelho do Estado assistencialista sem possuir interesses ou projetos políticos para a coletividade ${ }^{18}$. O Estado aparece na realidade da comunidade de forma fragmentada não representando uma entidade social mais ampla, ou seja, uma associação política. Em outras palavras, tal Estado não existe em Quinta Lebrão como categoria social, tornando-o incapaz de oferecer a unicidade necessária à noção de justiça em todos os aspectos demandados pelos moradores, proporcionando, através de uma complexa estrutura de mediação, o surgimento do líder comunitário cristão, agente constituído pela fé, que, negando a política, consegue, no jogo complexo das mediações, realizar a justiça demandada pela comunidade.

\section{Referências Bibliográficas}

BOURDIEU, Pierre. A Economia das Trocas Simbólicas. São Paulo: Ed. Perspectiva, 1992.

\footnotetext{
17 A experiência dos juizados especiais é marcada por uma grande demanda da população, significando, segundo Werneck Vianna (1999), a apresentação do Poder Judiciário como caminho pedagógico para a consolidação da cidadania.

${ }^{18} \mathrm{O}$ imaginário que associa a pobreza ao crime e que marca simbolicamente o campo da desordem, impõe à comunidade e às suas instituições a tarefa de ordenação moral e defesa dos membros da comunidade contra possíveis abusos de poder. Confusões, distúrbios e brigas dos mais vários tipos fazem com que as duas instituições principais da comunidade, ou até os próprios vizinhos, se mobilizem para apaziguar ânimos antes que se chame a polícia, dissociando o crime e a desordem da favela. Diante de alguns problemas policiais, as lideranças locais, articuladas com o mundo social se mobilizam para executar a mediação com o Estado, através da assistência judicial de advogados "dativos".
} 
BURGOS, Marcelo Baumann. "Dos Parques Proletários ao Favela-bairro; as políticas públicas nas favelas do Rio de Janeiro". In: Zaluar, Alba e Alvito, Marcos. Um século de favela. Rio de Janeiro, Fundação Getúlio Vargas, 2000.

LACOMBE, Marcelo. A Inclusão Marginal e a Cidade: O Lugar da Margem e os Desencontros do Brasil Urbano. Dissertação de Mestrado defendida no Programa de PósGraduação em Sociologia do IUPERJ em 1999. Orientadora: Profa. Dra. Lícia do Prado Valladares.

PRANDI, Reginaldo \& PIERUCCI, Flávio. Realidade Social das Religiões no Brasil. São Paulo: HUCITEC, 1996.

SANTOS, Boaventura de Souza. O discurso e o poder; ensaio sobre a sociologia da retórica jurídica. Porto Alegre, Fabris, 1988.

TOCQUEVILLE, Alexis de. A Democracia na América. São Paulo: EDUSP, 1977.

VALLADARES, Lícia do Prado. "Cem Anos Pensando a Pobreza (urbana) no Brasil”. In: BOSCHI, Renato. Corporativismo e Desigualdade: A Construção do Espaço Público no Brasil. Rio de Janeiro: Rio Fundo Editora/IUPERJ, 1991.

VIANNA, Luiz Werneck et alii. A Judicialização da Política e da Relações Sociais no Brasil. Rio de Janeiro: Ed. Revan, 1999.

WEBER, Max. A Ética Protestante e o Espírito do Capitalismo. (Edição de Antônio Flávio Pierucci). São Paulo: Ed. Companhia das Letras, 2004.

WEBER, Max. Economia e Sociedade. Brasília: Editora UnB, 1991.

WEBER, Max. Ensaios de Sociologia. Rio de Janeiro: Guanabara,1982. 